\title{
Northern Telangana, an Iron and Crucible Steel Production Landscape in India
}

\author{
Gillian JULEFF, ${ }^{1)^{*}}$ Sriperumbudur JAIKISHAN, ${ }^{2)}$ Sharada SRINIVASAN, ${ }^{2)}$ Srinivas RANGANATHAN $^{2 l}$ and \\ Brian GILMOUR ${ }^{3)}$
}

1) University of Exeter, Laver Building, North Park Road, Exeter EX4 4QE, UK.

2) National Institute of Advanced Studies, IISc, Bangalore 560012, India.

3) Research Laboratory for Archaeology, University of Oxford, UK.

(Received on November 30, 2013; accepted on March 3, 2014)

\begin{abstract}
Northern Telangana now lies in the remote rural heartland of India but is world renowned for its role in the past as a region of iron and crucible steel production, recorded in historical accounts and field investigations by first Thelma Lowe and then S. Jaikishan. In 2010 a joint team from University of Exeter and NIAS (National Institute of Advanced Studies), Bangalore, carried out a six-week archaeological field survey in the area that recorded 245 locations of which 183 are associated with metal-working. Locations of primary iron smelting dominated the survey results, with crucible steel manufacture forming c. $20 \%$ of the records. Further analysis is needed to resolve variations in smelting technologies but differences can be observed between smelting locations within settlements and those in more remote forested areas. A wide range of technologies are indicated by differences in tuyere size and shape, and techniques of furnace wall construction. The crucible steel-making locations show at least two different traditions using small, thin-walled crucibles and large, conical-lidded crucibles. This paper describes a preliminary assessment of the survey data.
\end{abstract}

KEY WORDS: crucible steel; iron smelting; India; field survey.

\section{Introduction}

Crucible steel remains one of the most enduring research topics in the field of archaeometallurgy. Historically approached from the point of view of its manifestation as the raw material of superior and highly-prized swords of the Islamic world, its distinctive microstructure made it soughtafter subject matter for early developers of metallography. ${ }^{1,2)}$ More recently, as archaeometallurgy has begun to emerge from the laboratory to examine where and by whom metals were produced there has been a shift in focus towards understanding crucible steel as a technological process rather than as a material. Starting from historical accounts, it has been possible to identify regions and sites where crucible steel was produced and through archaeological fieldwork begin to investigate the physical residues of the process at its points of origin. ${ }^{3,4)}$ What fieldwork does is remind us that crucible steel manufacturing rarely exists in isolation and is more likely to be one element of a local or regional production system that is dependent on locally-available resources and results in more than one end-product. Understanding the wider techno-cultural context of crucible steel production is the approach adopted by the Pioneering Metallurgy project, a UKIERI-funded (UK India Education and Research Initiative) collaboration between the University of Exeter and NIAS (National Institute of Advanced Studies), Bangalore.

* Corresponding author: E-mail: g.juleff@ex.ac.uk

DOI: http://dx.doi.org/10.2355/isijinternational.54.1030
Crucible steel is now known to have been manufactured across a large swathe of Asia, from Uzbekistan ${ }^{5}$ in Central Asia to Sri Lanka in the Indian Ocean. ${ }^{4)}$ Although it is true that recorded field evidence concentrates towards the northern and southern extremes of this territory, apparently corresponding with the two main trade routes connecting East and West - the northern overland Silk Road and the southern maritime Silk Route. The area selected by Pioneering Metallurgy, on current knowledge, forms the northern extent of the southern region of crucible steel manufacturing. This paper describes the field survey carried out by the project in 2010 and discusses preliminary observations on the data gathered. ${ }^{6}$

\section{Northern Telangana - Environment and Historical Background}

Northern Telangana comprises four districts; Karimnagar, Adilabad, Nizamabad and Warangal, on the northern border of what was at the time of the 2010 field survey still Andhra Pradesh but is now part of the newly created state of Telangana (Fig. 1). Topographically and geologically Northern Telangana lies on the Deccan Plateau, a vast area of central peninsular India made up of basaltic and granitic rocks which host a wealth of minerals including significant deposits of iron ore. In Northern Telangana two iron ore types are common. The first are massive outcrops of rich banded magnetites that can weather to fine magnetite sands. The 


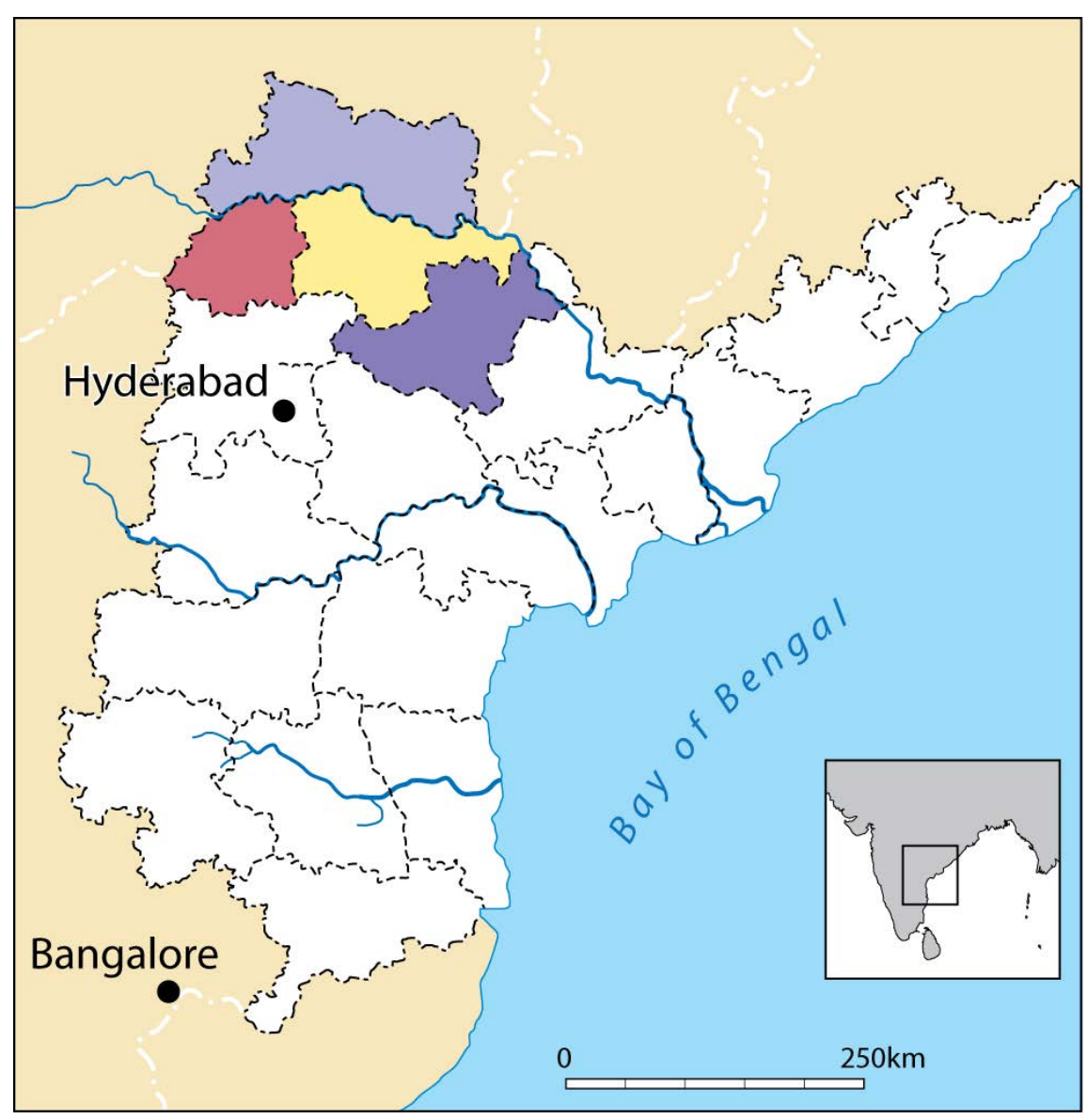

Fig. 1. The four districts of Northern Telangana where field survey was conducted. (Online version in color.)

second are hard-cap lateritic deposits of weathered graniticgneisses that can concentrate iron to $60 \%$ and higher. While there is a degree of overlap of the two types, the banded magnetite formations predominate in the north of the region while the lateritic ores are more prevalent in the south. The field evidence suggests both types have been widely exploited in the past without need for deep mining.

In terms of natural and human environment Northern Telangana lies in what is now the remote rural heartland of India and is a landscape of scattered agricultural villages of mixed occupational groups, interspersed with tracts of teakdominated forest and bisected by the west to east flowing Godavari river. That the area was settled well into the past is evidenced by the plethora of small abandoned irrigation reservoirs seen both on the ground and recorded on early topographical maps. While there have been few intensive archaeological surveys of the area there are known megalithic burial sites indicative of an Iron Age, iron-using culture which, although not clearly dated, is presumed to precede an Early Historic settlement phase. Of the latter, Kotilingala, an enclosed habitation site on the banks of the Godavari in Karimnagar district, is best known and dated to the early centuries BCE when the region formed part of the core of the post-Mauryan Satavahana kingdom. Through the earlymedieval and medieval periods the larger Deccan region fell under a succession of ruling dynasties and the ebb and flow of power resulted in numerous minor feudatories vying for local dominance and a landscape rich with forts and a distinctive tradition of large forge-welded cannons. ${ }^{7)}$ During this period Northern Telangana's link to the outside world was via the Godavari to the trading ports of the east coast, most notably Masulipatam. With the eventual establishment of the Qutb Shahi kingdom in 1518, with its new capital of Golkonda (modern-day Hyderabad) and later the Nizamate of Hyderabad, a stable Telangana thrived and enjoyed the profits of well-managed trade links.

Against this background of shifting and ultimately consolidating polities, Northern Telangana has been consistently associated with the production or iron and steel and the trade in ingots of high-carbon steel. Prior to any field surveys this was known through historical documentation, particularly firsthand accounts from European travelers visiting or doing business in the region. These accounts cluster in the seventeenth century, as the activities of the Dutch East India Company expand into the Bay of Bengal and Southeast Asia, and include mentions of the village of Konasamudram in Nizamabad district as an established steel-making centre or give descriptions of the trade in steel ingots from the Kingdom of Golkonda through the port of Masulipatam. Accounts include those of Floris, Havart (who visited Konasamudram in 1667), Tavernier and Thevenot. ${ }^{8-11)}$ While there is recognition in these accounts of the special quality of the steel and thus some attention paid to the mode of its manufacture, it is the nature and volume of the trade that takes precedence.

For a more thorough description of the manufacturing process the key account is that of Dr Voysey, ${ }^{12)}$ an English surveyor who visited Konasamudram three times somewhat later between 1820 and 1823 . Voysey describes the size and shape of the crucible furnace, the clay used in its construc- 


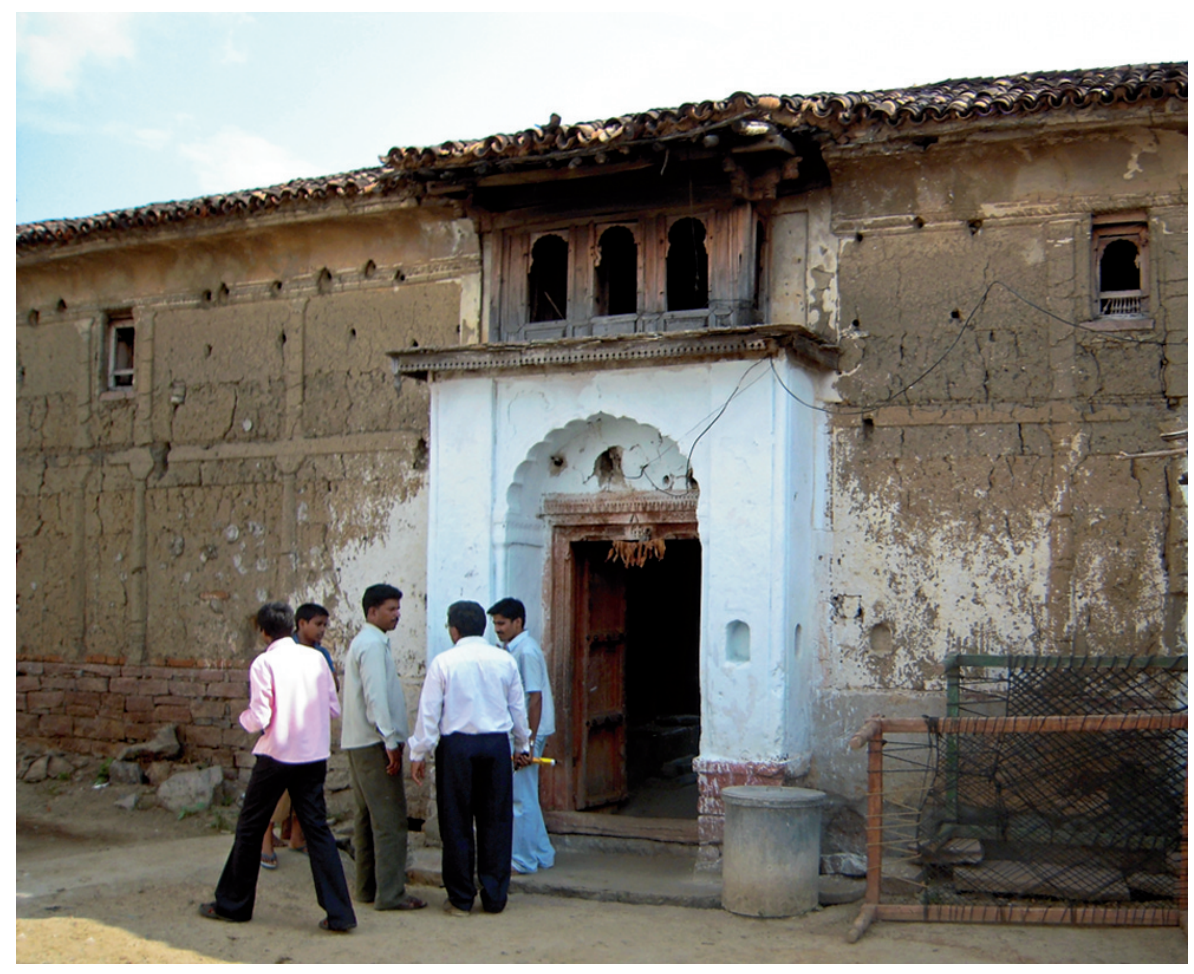

Fig. 2. Elaborate trader's house in Konasamudram. (Online version in color.)

tion, the position of the tuyeres and type of bellows used. He also describes that the crucibles are charged with two kinds of iron, one an amorphous and porous mass of reddish-grey colour derived from iron sand (presumably magnetite) from a named location, and the second, a moderately compact iron with a brilliant white fracture procured from ore found in iron clay (presumably lateritic ore), again from a named location. The combining of two different forms of iron is most often interpreted as indicating a co-fusion process to create a steel product intermediate between cast and wrought iron. In truth, neither of the two forms of iron described by Voysey have yet been unequivocally identified. Voysey does not tell us how either of them are produced and it is not yet accurate to assume them to be cast and wrought iron, and to expect both 'bloomery' and 'blast' furnaces. As with the earlier recorders, Voysey makes certain to comment on the dynamics of the trade in steel, saying "We have found in the village, in 1820, Haji Hosyn, from Ispahan, engaged in the speculation; and it must have answered his purpose, as he was here again in 1823". The important place of the steel trader in the life and industry of Konasamudram is reflected in the rare survival of an unusually large and ornamented trader's house of mud construction still standing in the heart of the village (Fig. 2).

\section{Previous Fieldwork}

The first concerted investigations into the iron and steel industries of Northern Telangana took place in the 1980's and were conducted by Thelma Lowe of University of California, Berkeley. ${ }^{13,14)}$ Lowe's aim was to record and investigate the field remains of the industry and after several seasons of intrepid exploration she had amassed a substantial database of records and material. Sadly, Thelma is no longer with us and the authors here pay tribute to her truly 'pioneering' work which formed a part of the inspiration for the current project. Lowe's work spanned from field survey of sites and collection and analysis of samples, to a detailed study of the historical sources. According to her manuscript reports Lowe had identified 74 smelting sites on 14 of which there had also been crucible steel production. The first author here was fortunate to accompany Thelma during a brief field visit in 1989 and was profoundly struck by the scale and diversity of the technological evidence and the excellent preservation of many of the sites.

In more recent years historian and resident in Northern Telangana, Dr S. Jaikishan, has sustained continuing field research into the political, socio-economic and technological history of the region, including the making of crucible steel as part of the fabric of local culture. His publications have brought the archaeometallurgical record of Northern Telangana to a wider Indian and international audience and added the names of many more villages in the four districts where iron and steel were prodcued. ${ }^{15)}$ It was through Dr Jaikishan's collaboration and generous offices that the UKIERI Pioneering Metallurgy project established a field base at Dharmapuri and undertook the six-week Telangana field survey during the first months of 2010 .

\section{Field Survey 2010: Aims and Methods}

The aim of the survey was to identify and gather data that would make it possible to characterise the archaeometallurgical landscape of the area. This character would be defined in terms of the nature, range and interconnections of the technologies present; the spatial and temporal distribution of variations in technology and scale of production; and the contextual relationship between metallurgy and settlement distribution and character.

In building on the work of Jaikishan, the purpose of the 
survey was not to explore for new sites but to visit known sites to carry out systematic recording and sampling. However, inevitably there were occasions in the course of the work when new locations were identified. The survey focused primarily on a core area of c. $30 \mathrm{~km}$ diameter, centred on Dharmapuri in Karimnagar district and straddling both banks of the Godavari. The area chosen was not only readily accessible from the field base but was also contiguous with the core area examined by Lowe and as such will ultimately extend the knowledge base for Northern Telangana, incorporating large samples from both the lateritic and banded magnetite ore regions. In addition, survey was extended from the centre, up to c. $100 \mathrm{~km}$ distance in some cases, to examine specific known locations of interest, including the village of Konasamudram to the southwest of the core area. The strategy followed what can best be described as reconnaissance survey and was based on experience gained by the first author during similar field surveys in Sri Lanka. ${ }^{16)}$ Systematic grid-style transect walking was unrealistic but all daily traverses by vehicle and on foot were recorded using GPS. Data was gathered simultaneously by all team members in field notebooks using a continuous expansive narrative approach. The narrative began with the departure from base camp each day and recorded routes traveled, significant landmarks, landscape features, changes in land use and agriculture, village settlements and individuals encountered in the course of a day. These contextual narratives are invaluable in analyzing the field data and allow close scrutiny and corroboration of a wide range of observations.

Where sites of interest, including all sites associated with iron and steel production, were encountered these were recorded as 'locations' and identified by a 'date/location' number, using the date followed by a sequential number specific to that date, e.g. 1-2-10 (1) or 5-3-10 (4). This avoided assigning 'site' status at the outset and consequently early preclusion of data deemed as 'non-site' status. It also allowed multiple loci within a settlement or larger metallurgical complex to be recorded separately rather than being subsumed within a general account of the whole. This also ensured that sites and site names did not become synonymous and interchangeable with village names. As an example of this, the village of Konasamudram has long been synonymous with crucible steel manufacturing and is thus widely regarded as a crucible steel site. Our traverses within and around the outskirts of the village recorded a number of locations associated with both smelting and crucible steel. Without further analysis of the data it is not clear whether these locations were technologically contiguous or chronologically separated. By maintaining them as separate location records the possibility of fine resolution in the analysis stage is preserved. ${ }^{6)}$

At the end of each day of the survey the information in each team member's field diary was amalgamated and transcribed into a single project notebook using the same narrative approach. The resulting records, while expansive and arguably old-fashioned, are comprehensive and readily accessible, and are reinforced by digital GPS and photographic datasets. Thus, with the added use of Google satellite images, it is possible to recreate the events and progress of each day of the survey.

\section{Field Survey 2010: Collection of Technological Debris}

At the majority of locations where technological debris was encountered surface samples were collected. To approach an unbiased sampling regime and allow inter-site comparisons, bulk collections of multiple fragments from one point were retrieved. In many instances, in addition to bulk assemblage samples, distinctive selected samples were collected of near-complete examples of consistent forms. As little or no dating exists for many of the sites, pottery sherds were also collected in the hope that they may assist in creating a relative chronology. Over $1500 \mathrm{~kg}$ of material was collected in the course of the survey. All the material was washed and subjected to rapid preliminary macro-morphological classification during the survey. This involved laying out each assemblage sample by type, e.g. slag, refractory, ore etc., photographing and then recording the whole in terms of relative proportions of type, presence or absence of types, and condition and degree of fracture. Individual elements within the assemblage could then be described for specific features, e.g. dominant tuyere or crucible sizes, or thickness of furnace walls etc., followed by decisions on discard and retention. ${ }^{17)}$ A large proportion of the original collected sample has been retained for further morphological, microstructural and compositional analysis.

\section{Field Survey 2010: Ethnometallurgy}

An integral component of the fieldwork was a survey of extant iron-working communities. The aim was to record as far as possible the presence, lives and working practices of the last generation of working rural blacksmiths and the descendants of iron smelters. Gathering ethnometallurgical data primarily involved interviewing blacksmiths in their residences or work-spaces but also included conversations with village elders, toddy tappers, owners of land containing slag or crucible heaps and other local residents with knowledge or memory of the past smelting and blacksmithing. Twenty interviews were conducted, eleven with traditional blacksmiths, including one itinerant blacksmith. Each interview began by asking the blacksmith if they were happy to talk about their work and then, with consent, followed a flexible format of consistent topics encompassing blacksmithing traditions of the family and village, memory of past smelting and smithing industries, objects made and repaired, clients and remuneration system, source of materials and apprenticeship processes. In addition to the interviews, blacksmiths were also observed and recorded going about their work (Fig. 3) and measured sketch plans made of their work-spaces.

The data collected through the ethnometallurgical survey is complex and detailed and will form a discrete element of the research project. ${ }^{18)}$ The following observations give a hint of the richness of the record. The blacksmiths of Northern Telangana, like most of the blacksmith communities of south India, fall within the Viswakarma (the Hindu god of arts and crafts) caste group and comprises five craft communities; blacksmiths, goldsmiths, bronze-smiths, carpenters and stonemasons or sculptors. Intermarriage is practiced among the three metal craft communities but apparently is not encouraged with the non-metal craft groups (carpenters 


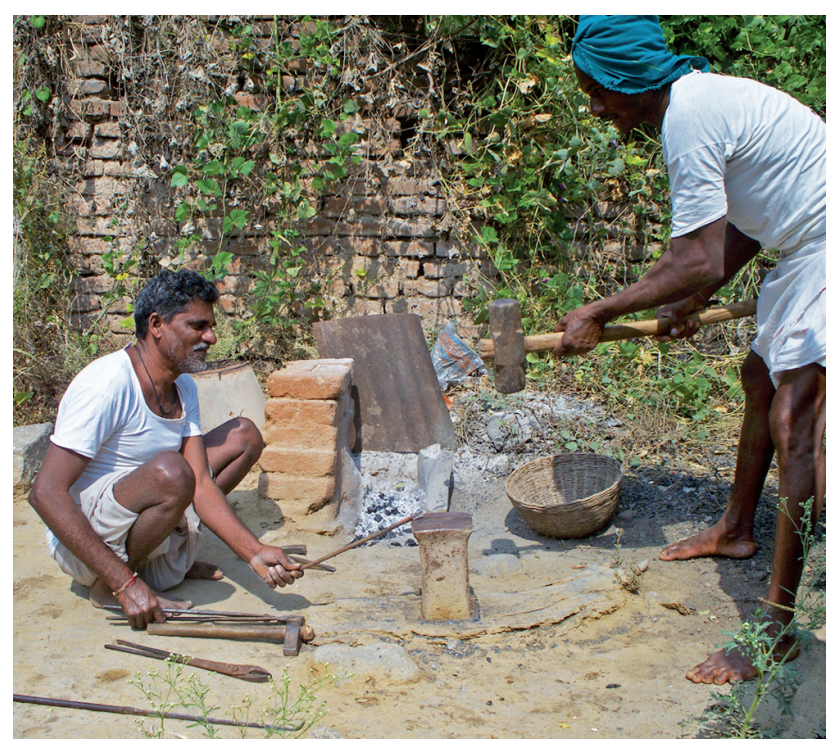

Fig. 3. Traditional village blacksmiths at work. (Online version in color.)

and stonemasons), and marriage outside the caste is strongly discouraged. The Viswakarma of the region, including the blacksmiths, wear sacred threads like the Brahmins and a sense of strong inter-caste competition with the Brahmins was observed.

Blacksmith communities tend to occur as close clusters within larger rural settlements. In each village the community is stratified according to seniority and headed by a body of elders (three or four senior smiths) who preside over communal meetings, generally held on every new moon evening and in the premises of the temple of their goddess, Mammayee. The elder blacksmiths are responsible for making important decisions regarding community disputes, auspicious and inauspicious days, and festivals. In most cases their decisions are deemed as final and unassailable. ${ }^{18)}$

Following the main survey there was also an opportunity to record the Mammayee festival, the annual rejuvenation festival of the blacksmith communities of the region dedicated to their goddess, Mammayee. The festival takes place during the last days of the Telugu calendar in early March and comprises a complex set of rituals around stopping work and closing the forge so that the smiths and their tools can attend the temple to worship, receive blessings and tie new sacred threads, on both smiths and tools. This is followed by the inauguration and lighting of the newly cleaned and decorated smithy, the forging of the first item and its exchange with the farmer-customer for food in the form of rice, pulses and spices. The fascinating record of this important festival is elaborated on more fully in the first project interim report. ${ }^{18)}$

\section{Initial Treatment of Survey Data}

In our attempt to understand the nature of the development of iron and steel-making in Northern Telangana the field survey has given us a number of strong datasets that have been distilled into four distinct themes; landscapes, locations, collected material and ethnographies. Work on these datasets since the field survey has followed a method- ology of systematic digital archiving, deconstruction of the data into component elements and cross-correlation of datasets. Ultimately the primary product of this process will be permanent project archives, accessible through a conventional gazetteer of sites which will, in turn, provide material for broad interpretational syntheses of iron and steel production and reconstructions of regional technologies.

On returning from the field the core source of data comprised the hand-written narratives in the project notebooks and diaries, with the supporting GPS traverses and logs. The first task was to transpose this into a digital form to create discrete 'location' records. A digital proforma 'location' record form was designed onto which information culled from the diaries and other survey archives could be systematically re-ordered to capture four tiers of data: locational and administrative, e.g. GPS records, place-names, location and landscape description; site description, including site type and sub-type, size and condition, descriptions of features and visible assemblages; sampling level and collected material giving cross-references to sample records; and finally cross-references to other data sources, e.g. photographs, maps, sketch plans, documentary references and interview records. The form also has provision for noting associated records, thus providing a first opportunity to identify site groupings based on proximity and shared features or assemblage traits. This database, or gazetteer, is in the process of compilation and will remain dynamic while research continues and it is hoped it will in time be expressed through a GIS platform.

\section{Preliminary Observations and Discussion}

During the field survey of 2010 a total of 245 'locations' were recorded. Of these 183 are directly associated with iron and crucible steel production. The non-iron and crucible steel locations include a wide range of evidence including geological features; historic settlements; individual structures such as temples, fort bastions and manor houses; and locations with ethnometallurgical associations, e.g. working smithies and interview settings. The observations made here derive from the first assessment of the material from the datasets relating to locations and the collected material. Reaching the ultimate project objective of characterisation of the archaeometallurgical record of Northern Telangana will require integration and interpretation of data from all the datasets and is a continuing process.

At a general landscape level there is a noticeable distribution pattern of metallurgical sites between those located in more remote forested areas away from current settlements and those within or on the peripheries of settlements. As a preliminary observation, evidence for crucible steel production falls within the latter group and the former appears to be primarily devoted to smelting but the veracity of this interpretation will require further close scrutiny of the technological debris assemblages. The question this division invites is whether remote smelting sites can be associated with the contribution of tribal or marginal communities whose role is being studied in depth as part of the continuing research agenda.

At site level, by using the system of 'location' records decisions on assigning 'site' status remain open to interpre- 


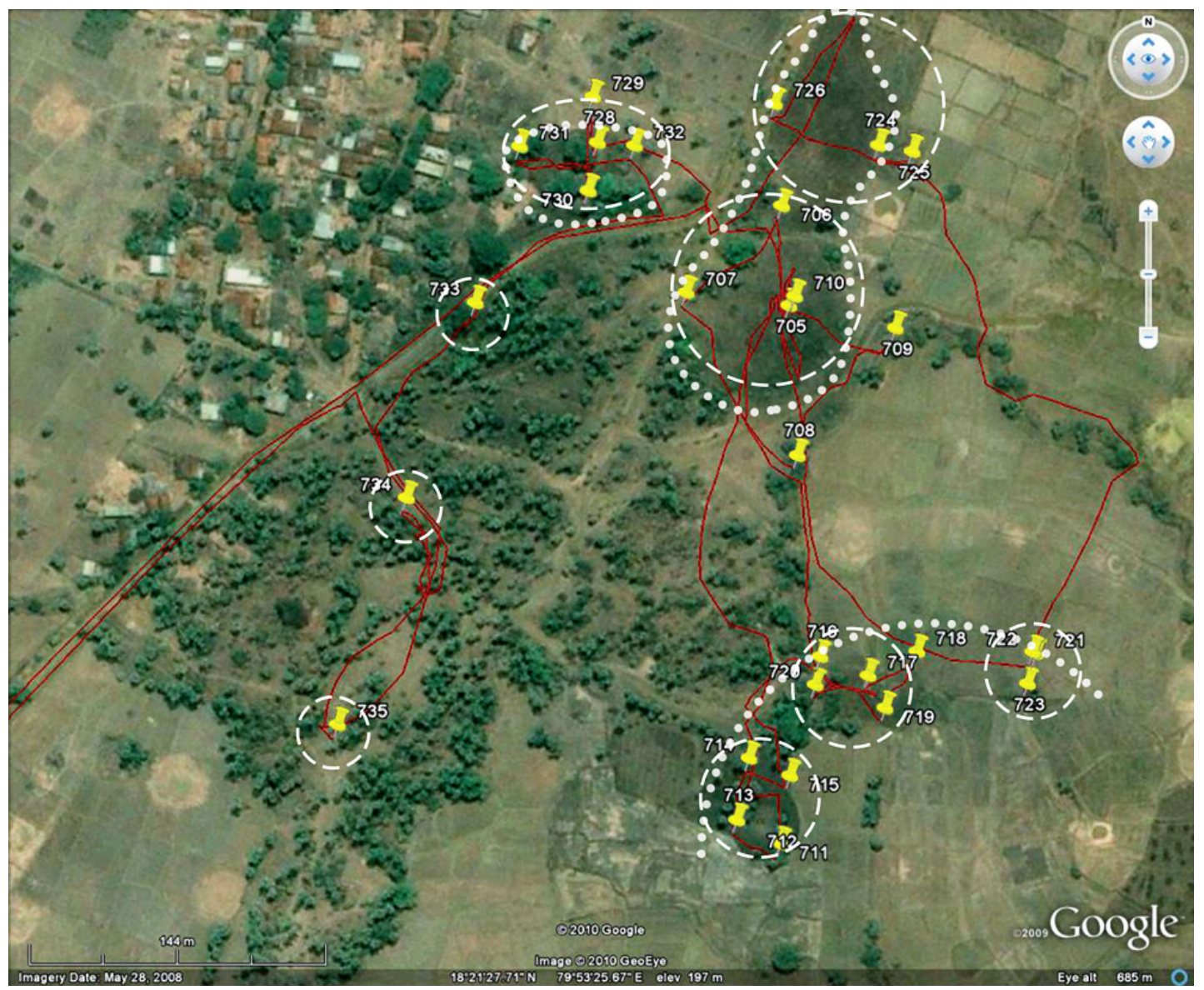

Fig. 4. Parasurampalli, GPS survey traverses and locations with working interpretation of a large smelting and crucible steel complex. (Online version in color.)

tation. The records show that frequently 'locations' group together in complex 'sites' made up of separate elements or 'sub-sites'. These separate elements may be differentiated by technological processes, e.g. smelting and crucible steel making, or they may display the same technology distributed over several loci, as in a group of slag heaps. Determining how the elements within a complex site relate to each other is one of the tasks of interpretation. Is the separation chronological and reflects development over time, or is it social and reflects the working practices of different kinship groups, or does the explanation lie in technological considerations? One example of a large metal-working complex is Parasurampalli in Warangal district (Fig. 4). In an extensive area of toddy palm cultivation on the edge of the present village, 10 'locations' were recorded. These included large but badly damaged (bulldozed) slag heaps, well-preserved discrete deposits of crucible fragments and peripheral scattered spreads of secondary material, which may equally represent remnants of in situ slag heaps. Combining macro-morphological data with location data it is possible to propose a division between smelting and crucible steel with the later forming an arc of activity at one extreme of the complex, with large-scale smelting occupying a more central position. Parasurampalli is only one example of several different forms of complex sites encountered during the survey.

At site sub-type level, technological processes are the determining factor, with the primary distinction being between smelting, smithing and crucible steel. Without introducing numbers of sites that may later be superseded, it is clear that the overall record is dominated by smelting with crucible steel sites forming in the region of $20 \%$ of the record (according well with Lowe's findings). Only two possible smithing sites were identified, both small and associated with past settlements. Undoubtedly other smithing sites exist but macro-morphological analysis has yet to identify typical assemblages.

Macro-morphological analysis has however begun to define patterns in the technological debris for smelting and crucible steel making. Slags form the largest body of material examined and these are dominated by material derived from furnaces capable of slag-tapping. A small number of sites display assemblages that do not include tap slags and slag that appears to have cooled inside the furnace. The distribution of both types appears at present to be dispersed across the survey area with no identifiable concentrations. One notable site of the non-slag tapping type is that at Buggaram in Karimnagar district.

Although only fragmentary material remains of the furnaces some striking consistencies across the survey have been discerned. Many furnaces have diameters less than $0.75 \mathrm{~m}$ and were constructed as detachable shaft structures placed over a semi-permanent basal stone plinth. These granitic basal stones were prone to heat damage and the fragments identified all bore heavy vitrification. These furnace shafts were formed by plastering clay around bundles of reeds or straw as indicated by striated impressions on inter- 


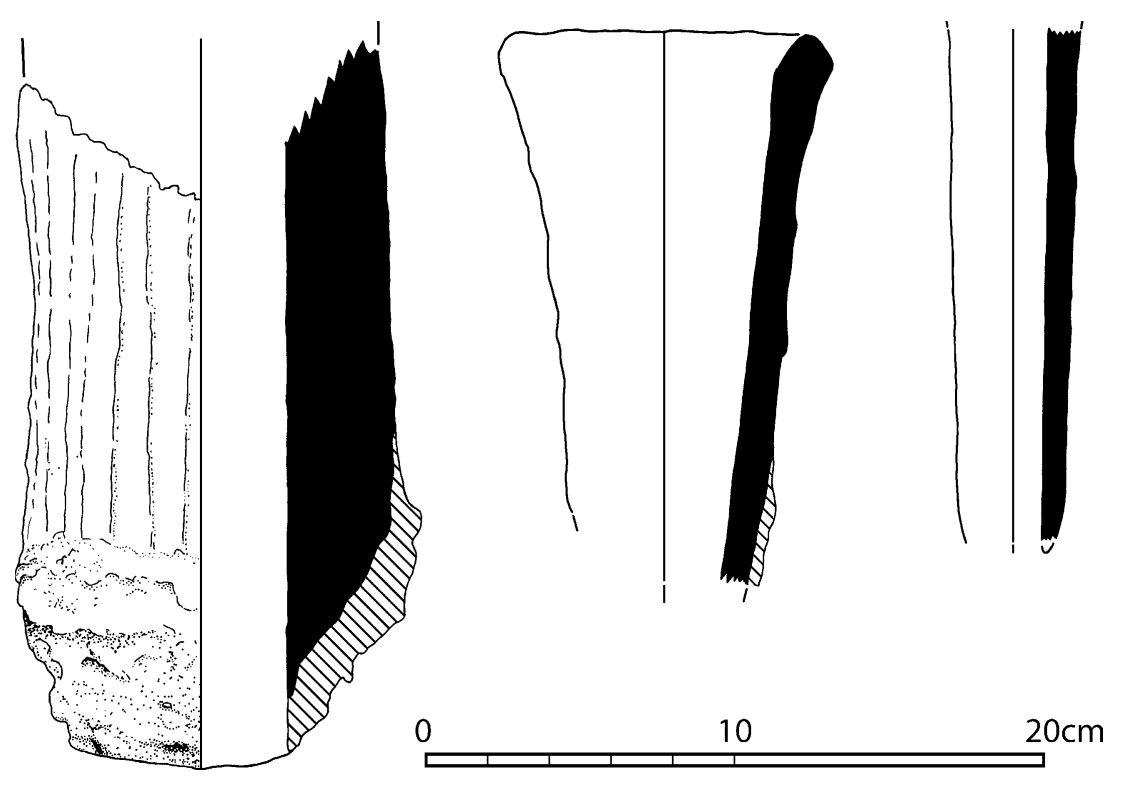

Fig. 5. Examples of the three forms of tuyere found during survey.

nal surfaces. An analogous furnace construction technique is described by Keen, ${ }^{19)}$ who observed it used by the Agaria tribal smelters in the region to the northeast of our survey area. At a small number of other sites coil-built furnace wall fragments were clearly identified. One of these was Buggaram, the non-slag tapping site already mentioned, and possibly reinforces Dr Jaikishan long-held view that this site is one of the earliest in the area by analogy with a coil-built furnace at the megalithic site of Naikund, Maharastra. ${ }^{20)}$

Of the refractory materials, tuyeres form a strikingly prominent component of the technological debris and those within the collected samples divide into three distinct forms. The forms are based on size and they range from exceptionally large tuyeres, through medium-size to very small tuyeres. The large tuyeres are thick-walled and parallel-sided and often have an internal bore of $>4 \mathrm{~cm}$ (Fig. 5). They are the smallest group of tuyeres but are distributed widely across the survey. In general they are most closely associated with sites where crucible steel making is evidenced but this is not exclusive. The largest group of tuyeres are the mediumsized examples (Fig. 5). These vary considerably in degree of taper and overall length but they are generally of medium wall thickness, tapering or flaring, and can be very heavily vitrified. Many have large segments of vitrified furnace wall remnants adhering to them and give the overall impression of high temperature, dynamic processes. They are predominantly associated with smelting sites. The third group are the very small tuyeres (Fig. 5). While these also vary in size, they are consistently parallel-sided and less heavily vitrified than the medium-size tuyeres. Their distribution is not widespread but on the sites where they do occur they appear in abundance. Preliminary assessment suggests they are associated with non-slag-tapping smelting assemblages.

Finally, it has emerged from the macro-morphological analysis that the crucibles fall into two distinct type groups. The first of these is well known as the material commonly seen at Konasamudram but which occurs on a number of other sites. These crucibles are thick-walled and have disproportionally large conical lids that are luted and fused onto the crucible body and consistently show tong indenta-

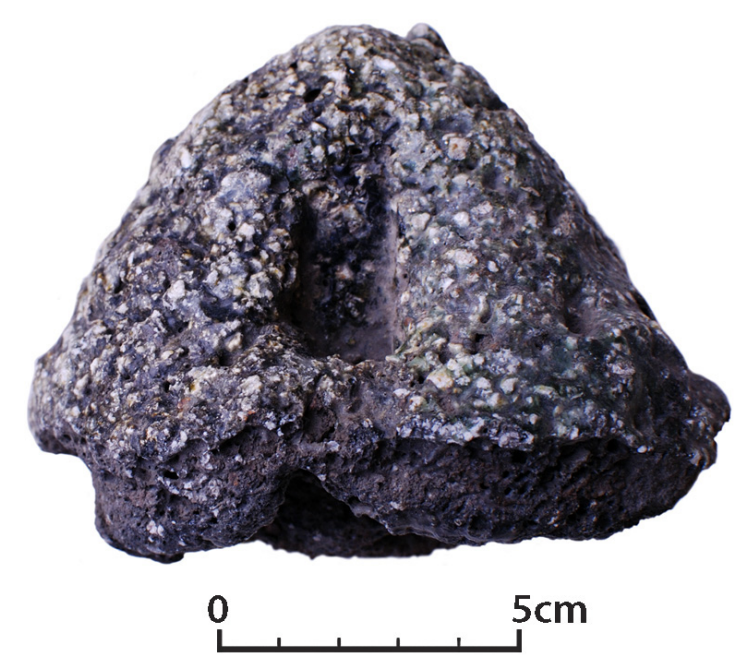

Fig. 6. Example of conical crucible lid showing indentations caused by use of tongs to remove the crucible from the furnace while still soft. (Online version in color.)

tions indicating that individual crucibles were handled while still soft (Fig. 6). These crucibles can vary significantly in size and range from c. 3 to $15 \mathrm{~cm}$ in internal diameter, but with a clear tendency towards the large end of the scale. The second and larger group in terms of site distribution comprises more standardized, small to medium-sized, thinwalled crucibles. The lids of these thin-walled crucibles are also luted onto the body of the crucibles but they are not of the large conical form. These crucibles do not show tong marks and are fired in batches stacked into a furnace, as opposed to the Konasamudram type that are handled individually, resulting in clusters of fused crucibles that had to be smashed open to retrieve the ingot material inside (Fig. 7). On present assessment, thin-walled crucibles appear most often in close proximity with smelting evidence while the thick-walled examples occur at complex sites where there is greater spatial separation of technologies suggesting more standardised production. 


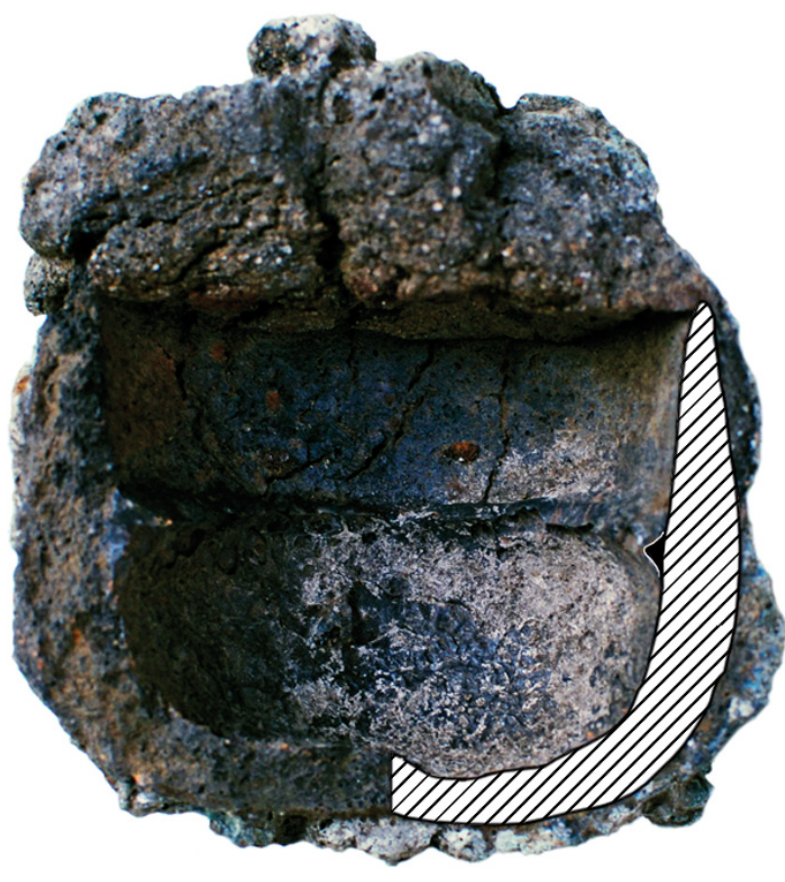

Fig. 7. Example of thin-walled crucible (internal diameter $5.5 \mathrm{~cm}$ ). (Online version in color.)

\section{Conclusions}

Pioneering Metallurgy is a continuing project and much remains to be done to verify if the observations made above continue to hold true and to achieve a full analysis and characterization of iron and crucible steel production in Northern Telangana. However, the field survey of 2010 and the data derived from it indicate a rich and complex techno-cultural landscape of which crucible steel is one of a number of components. At this stage the most problematic aspect of the research is resolving the chronological span of the evidence to enable us to track technological change over time. In the absence of cultural markers (coins or a good local pottery typology) a campaign of scientific dating is required to place the locations and sites within a chronological frame- work. Returning to the original motivator for the survey, the wider study of crucible steel, from the results thus far, a clear division between 'bloomery' and 'cast iron' smelting to supply two types of iron as feedstock for a co-fusion crucible process is not yet discernible in the record and we should remain cautious in using these terms. However, given the wealth of the archaeological record of the region, it will be possible ultimately to resolve this question and move away from over-reliance on the documentary accounts alone.

\section{REFERENCES}

1) C. S. Smith: A History of Metallography - the Development of Ideas on the Structure of Metals before 1890, University of Chicago Press, Chicago, (1960).

2) R. A. Hadfield: J. Iron Steel Inst., 85 (1912), No. 1, 134

3) A. Coomaraswamy: Medieval Sinhalese Art, 3rd ed., Pantheon Books, New York, (1979).

4) M. L. Wayman and G. Juleff: J Hist. Metall. Soc., 33 (1999), No. 1, 26.

5) Th. Rehren and O. Papachristou: Metalla (Bochum), 7 (2000), No. 2, 55.

6) G. Juleff, S. Srinivasan and S. Ranganathan: Pioneering Metallurgy, Telangana Field Survey Interim Report, National Institute of Advanced Studies, Bangalore, (2011).

7) S. Jaikishan: Indian J. Hist. Sci., 40 (2005), No.4.

8) W. H. Moreland: Peter Floris, His Voyage to the East Indies in the Globe 1611-1615, Vol. 2, No. 74, Hakluyt Society, London, (1934).

9) D. Havart: Open Ondergang van Coromandel Vol. 3, Hoorn, Amsterdam, (1693).

10) J-B. Tavernier: Six Voyages en Turquie, en Perse et aux Indes, Paris, (1679).

11) J. de Thevenot: Indian Travels of Thevenot and Careri, ed. by S. N. Sen, National Archives of India, New Delhi, (1949).

12) H. W. Voysey: J Asiatic Soc. Bengal, 1 (1832), 245.

13) T. L. Lowe: Ceramics and Civilization, ed. by W. D. Kingery, The American Ceramic Society, Pittsburgh, (1990), 237.

14) T. L. Lowe, N. Merk and G. Thomas: Materials Issues in Art and Archaeology II, ed. by P. A. Vandiver, J. Druzik and G. S. Wheeler, Materials Research Society, Pittsburgh, (1992), 627.

15) S. Jaikishan: Iron and Wootz Steel Industry in Northern Telangana, Telangana Jagrithi, Hyderabad, (2009).

16) G. Juleff: Early Iron and Steel in Sri Lanka: A Study of the Samanalwewa Area. AVA-Materialien 54, von Zabern, Mainz, (1998).

17) M. Cox and S. Haricharan: Pioneering Metallurgy, Telangana Field Survey Interim Report, ed. by G. Juleff, S. Srinivasan and S. Ranganathan, National Institute of Advanced Studies, Bangalore, (2011), 11.

18) T. Neogi and S. Jaikishan: Pioneering Metallurgy, Telangana Field Survey Interim Report, ed. by G. Juleff, S. Srinivasan and S. Ranganathan, National Institute of Advanced Studies, Bangalore, (2011), 15 .

19) J. Keen: The World of Iron, ed. by J. Humphris and Th. Rehren, Archetype, London, (2013), 97.

20) S. B. Deo and A. P. Jamkhedkar: Excavations at Naikund, Dept. of Archaeology and Museums, Govt. of Maharastra, Bombay, (1982). 